\title{
Localized Prostate Cancer Patients' Information in Urology Outpatient Practice-Results of a Nationwide Prospective Study in Germany
}

\author{
Jens Jaeger ${ }^{1}$, Lothar Weißbach ${ }^{2}$, Holger Pfaff ${ }^{1}$, Nicole Ernstmann ${ }^{1}$ \\ ${ }^{1}$ University of Cologne, Institute of Medical Sociology, Health Services Research and Rehabilitation Science (IMVR), Cologne, \\ Germany; ${ }^{2}$ Stiftung Maennergesundheit, Berlin, Germany. \\ Email: jens.jaeger@gmx.com
}

Received February $13^{\text {th }}, 2013$; revised March $16^{\text {th }}, 2013$; accepted March $24^{\text {th }}, 2013$

Copyright (C) 2013 Jens Jaeger et al. This is an open access article distributed under the Creative Commons Attribution License, which permits unrestricted use, distribution, and reproduction in any medium, provided the original work is properly cited.

\begin{abstract}
Purpose: Many studies demonstrate the importance of an empathic communication with prostate cancer patients and show various information needs. Most of the studies are cross sectional. The present analysis aims to 1) provide detailed prospective data on the actual quality of patient information provided by urologists in private practice in Germany; and 2) explore sociodemographic, communicative, and health- and treatment related determinants of the quality of provider-patient-communication. Methods: HAROW is a prospective, observational study designed to collect clinical data and patient reported outcomes of different treatment options (hormonal therapy, active surveillance, radiation, operation, watchful waiting) for newly diagnosed patients with localized prostate cancer under real conditions. At 6-month intervals, general clinical data, patient reported outcomes and patients' assessment of patient-physician-communication are documented. A total of 1893 questionnaires at $\mathrm{t}_{0}$ (initial diagnosis) and $\mathrm{t}_{1}$ (six months after diagnosis) were analyzed. A linear regression model was estimated. Results: The mean age of the men was 68.38 years, and most lived with their spouse or partner (94.1\%). Most patients were informed about treatment options $\left(\mathrm{t}_{0} 96 \%, \mathrm{t}_{1} 93.2 \%\right)$, but much fewer received information about self-help groups $\left(\mathrm{t}_{0} 36.4 \%, \mathrm{t}_{1} 45.8 \%\right)$, rehabilitation $\left(\mathrm{t}_{0} 59.9 \%, \mathrm{t}_{1} 68 \%\right)$, and second medical opinion $\left(\mathrm{t}_{0} 57.2 \%, \mathrm{t}_{1} 59.3 \%\right)$. Older men $(\mathrm{p}=0.02)$ and men living alone $(\mathrm{p}=0.048)$ received less information than others. Physician empathy $(p=0.000)$ and prostatectomy treatment $(p=0.020)$ were positively associated with receiving more information. Conclusion: There is room for improvement in terms of informing prostate cancer patients about rehabilitation, second medical opinion and self-help groups. Urologists being empathetic share more information with their patients. Some patients receive less information than others, especially older patients living alone.
\end{abstract}

Keywords: Prostate Cancer; Patient Information; Empathy

\section{Introduction}

\subsection{Background}

At $26 \%$ of cases, prostate cancer is the most common form of cancer in men; in Germany, the disease has an annual incidence of 65000 cases [1]. It causes about $10 \%$ of cancer deaths in Germany and is one of the leading causes of cancer death in men [2]. The mean age of men diagnosed with prostate cancer is 69 years, and the disease is fairly rare in men under 50 years of age [1]. The associated mortality rates are dropping while age-standardized incidence rates are strongly rising; this is likely a result of PSA testing as a screening tool [1]. Prostate

*Disclosures: none. cancer primarily differs from other cancers by its slow tumor growth. Treatment options include radical prostatectomy, radiation therapy, hormone therapy, active surveillance, and watchful waiting or combinations of those options. For the metastatic prostate cancer, the chemotherapy can be used. Each treatment has specific advantages and risks about which the patient must be personally informed. Only patients who have been comprehensively informed can weigh benefits and risks as well as contribute to treatment success and rapid recovery and rehabilitation with minimal adverse effects [3].

\subsection{Information Needs}

Health services research has taken greater interest in 
cancer communication research in recent years, focusing on the importance of patient-centered communication $[4,5]$. In terms of communication with prostate cancer patients, the information needs of those men became subject to research in the last years. Previous studies show that increasingly, the majority of patients desire to play a more active role in the decision-making process ("shared decision making"), and few patients want to take a more passive role [6-9]. The willingness to actively participate in the treatment decision differs from individual to individual, but more information and a better understanding of the disease gives each patient the opportunity to participate [10]. Receiving the diagnosis of prostate cancer is a dramatic experience, and the time after diagnosis can be very difficult for patients [11]. On the one hand, patients have to deal with the cancer diagnosis; while on the other hand, treatment decisions have to be made. Good information management that is tailored to the individual patient can reduce fears and uncertainties [12], while insufficient or missing information tends to have the opposite effect. There are also indications that satisfaction with medical information has a positive effect on the men's quality of life [13].

What information do patients want? Feldman-Stewart et al. have extensively studied patients' information needs [14-16]. They found that it is virtually impossible to identify the information that is important and needed for each individual patient. Information needs were highly variable, so that from a total of 93 aspects, only a core of 20 questions that were important to $67 \%$ of patients could be identified. However, 91 questions were important to at least one study participant. The authors therefore concluded that the identified core of questions that was important to most patients does not adequately meet the information needs of each individual patient. Initial studies on this topic have now been conducted in German-speaking countries as well; their results are similar and show that information needs are highly variable and individualized [17]. Boberg et al. found that information needs are the most important needs of prostate cancer patients but are the ones most rarely met [18]. These findings are important in medical practice, as they suggest that the treatment provider must approach each patient individually without burdening him with excessive information. Existing studies disagree regarding the influence of the patient's sociodemographic characteristics, such as age, on his information needs, so physicians cannot use such characteristics to draw conclusions about the patient's needs. Patients listed the treating physician as their most important source of information $[7,19,20]$, and physician advice considerably influenced the patient's treatment decision [21].

Treating urologists bear extraordinary responsibility; in their conversation with the patient, they must deter- mine and satisfy the patient's information needs, close gaps in his knowledge, and determine the patient's willingness to play an active role. Health care professionals' opinions regarding the information needs of their patients seem to vary considerably as well. Feldman-Stewart et al. asked healthcare professionals to rank fictional patient questions about localized prostate cancer by importance. There was relative agreement between professional groups regarding the importance and the number of questions to be asked. Within the professions, however, there was significant variation in the importance rankings as well as the number of important questions. The authors concluded that patients in similar medical situations may receive very different information [22].

\subsection{Research Question}

The information needs of patients with localized prostate cancer have already been investigated in several studies that clearly demonstrated the importance of patient information. Some studies indicate that the majority of patients feel well informed, but that nevertheless, a considerable percentage of them are dissatisfied with the information [23,24]; in addition, there are concerns about the patients' ability to understand and process the presented information [25]. One study revealed a discrepancy between the importance of a piece of information to the patient and the patient's knowledge [26].

Most of the studies are cross sectional. The HAROW study (http://www.harow.de) allows us to prospectively investigate patient information about treatment options, rehabilitation, self-help groups, and obtaining a second medical opinion. These are basic aspects of care about which all patients should be informed. Actively participating in treatment decisions requires that the patient knows all treatment options. In accordance with the German Social Code Book (SGB, http://www.sozialgesetzbuch-sgb.de), every cancer patient is entitled to follow-up rehabilitation or rehabilitative services, which have been proven to contribute to the physical and psychological recovery of cancer patients [27]. They are also recommended by the "Interdisciplinary guideline (quality level S3) for the early detection, diagnosis, and treatment of prostate cancer" (http://www.awmf.org). Selfhelp groups positively affect the quality of life of patients $[28,29]$, and they contribute to patient information and to improved understanding of the disease [30].

The present study analyses the urologist-patient-communication in private practice in Germany and explores to what extent different groups of patients are getting informed by their physicians.

\section{Methods}

Data are collected within the HAROW study. The objec- 
tive of HAROW is to collect data for Germany by surveying 5000 patients with newly diagnosed localized prostate cancer to gain new insights about tumor characteristics, treatment strategies and their outcomes. Inclusion criteria are: newly diagnosed prostate cancer, localized prostate cancer (up to $T_{2 c}$ ), no metastatic disease $\left(\mathrm{N}_{0}\right.$, $\mathrm{M}_{0}, \mathrm{~N}_{\mathrm{x}}, \mathrm{M}_{\mathrm{x}}$ ), and informed consent. For each patient, the initial information is documented $\left(\mathrm{t}_{0}\right)$; every 6 months thereafter, a follow-up documentation is then conducted, in which data are collected again regarding the general health of the participant, tumor stage, quality of life, doctor-patient interaction, and treatment satisfaction [31].

Four questions measure patient information about possible treatment options, rehabilitation options, self-help groups, and obtaining a second medical opinion. Patients may respond with "Yes" or "No", depending on whether he was informed about that aspect by his physician. An index was calculated for $t_{0}$ and $t_{1}$ to comprehensively reflect the level of information provided to study participants in the first six months of diagnosis by summing up the number of points from the index at $t_{0}$ and $t_{1}$. A maximum of eight points were possible per patient $(0=$ no question answered with "Yes", $8=$ all questions answered with "Yes"). The health related quality of life is assessed with the EORTC-QLQ-C30 instrument [32], which includes physical, role, emotional, cognitive, and social functioning as well as global health status. The functions are rated on a scale of $0-100$, with higher scores indicating better function. For comparison purposes, we used reference data from Schwarz et al. for Germany [33]. Physician empathy is measured using the German-language CARE (Consultation and Relational Empathy) measure. The score is determined using a five-point Likert scale ( 1 = fully applies; 2 = largely applies; $3=$ partially applies; $4=$ hardly applies; $5=$ does not apply at all) [34].

A blockwise linear regression analysis was performed to examine relationships between patients' assessment of physician information and sociodemographic influencing factors (patient age, living situation, retirement status, comorbidities), selected treatment option, quality-of-life items, and physician empathy as rated by the patients. Statistical analysis was performed using IBM SPSS 19 for Windows.

\section{Results}

\subsection{Descriptive Statistics}

We analyzed the data of $\mathrm{n}=1893$ patients treated by a total of 293 urologists in private practice in Germany at $t_{0}$ and $t_{1}$. The mean age of the men was 68.4 years. The majority of men $(74.2 \%)$ is retired and is covered by statutory health insurance (86.1\%). Most study partici- pants lived with their spouse or partner (94.1\%). Most patients chose radical prostatectomy $(53.3 \%)$, followed by active surveillance $(14 \%)$, radiation therapy $(12 \%)$, hormone therapy $(7.7 \%)$ and watchful waiting $(4.8 \%)$. We also have $8.2 \%$ of missing data. Table 1 shows patients' comorbidities.

Figure 1 illustrates the results for physician empathy (CARE measure) and the functional items from the EORTC QLQ-C30. A comparison of the QLQ-C30 functional scales at times $t_{0}$ and $t_{1}$ reveals that none of the items substantially deteriorated or improved. Emotional functioning exhibits the largest difference in scores, with values of $76.13\left(\mathrm{t}_{0}\right)$ and $80.67\left(\mathrm{t}_{1}\right)$, but the difference is not clinically relevant ( $<10$ points). The quality of life of study participants does not seem to be substantially affected. Table 2 shows the results for physician empathy according to the CARE measure. Overall, physician empathy was rated high across treatment groups and for both measurement times. Radiation therapy patients exhibited the largest difference in empathy scores between $t_{0}$ and $t_{1}$, with the score dropping from 4.69 to 4.46 .

Figure 2 shows the percentage of patients informed for the four information questions at $t_{0}$ and $t_{1}$. At both measurement times, almost all patients had been informed about the various treatment options $\left(96 \% \mathrm{t}_{0}\right.$, $\left.93.2 \% \mathrm{t}_{1}\right)$. The information situation was considerably worse for the other three items (self-help groups, rehabilitation, second opinion), with the means calculated from the two measurement times showing that only slightly more than half of patients had been informed $(54 \%)$. The poorest patient information results were found for self-help groups $\left(36.4 \% \mathrm{t}_{0}, 45.8 \% \mathrm{t}_{1}\right)$.

Table 1. Comorbidities of study participants.

\begin{tabular}{lcc}
\hline Diagnosis & $\mathbf{n}$ & $\mathbf{\%}$ \\
\hline Diabetes mellitus & 194 & 10.7 \\
Peripheral vascular disease & 136 & 7.6 \\
Chronic Lung disease & 82 & 4.6 \\
Cardiac insuffiency & 80 & 4.4 \\
Myocardial infarction & 76 & 4.2 \\
Kidney disease & 54 & 3 \\
Liver disease & 38 & 2.3 \\
Ulcer & 29 & 1.6 \\
Connective tissue disease & 19 & 1.1 \\
Lymphoma & 6 & 0.3 \\
Leukämia & 4 & 0.2 \\
Hemiplegia & 3 & 0.2 \\
\hline
\end{tabular}




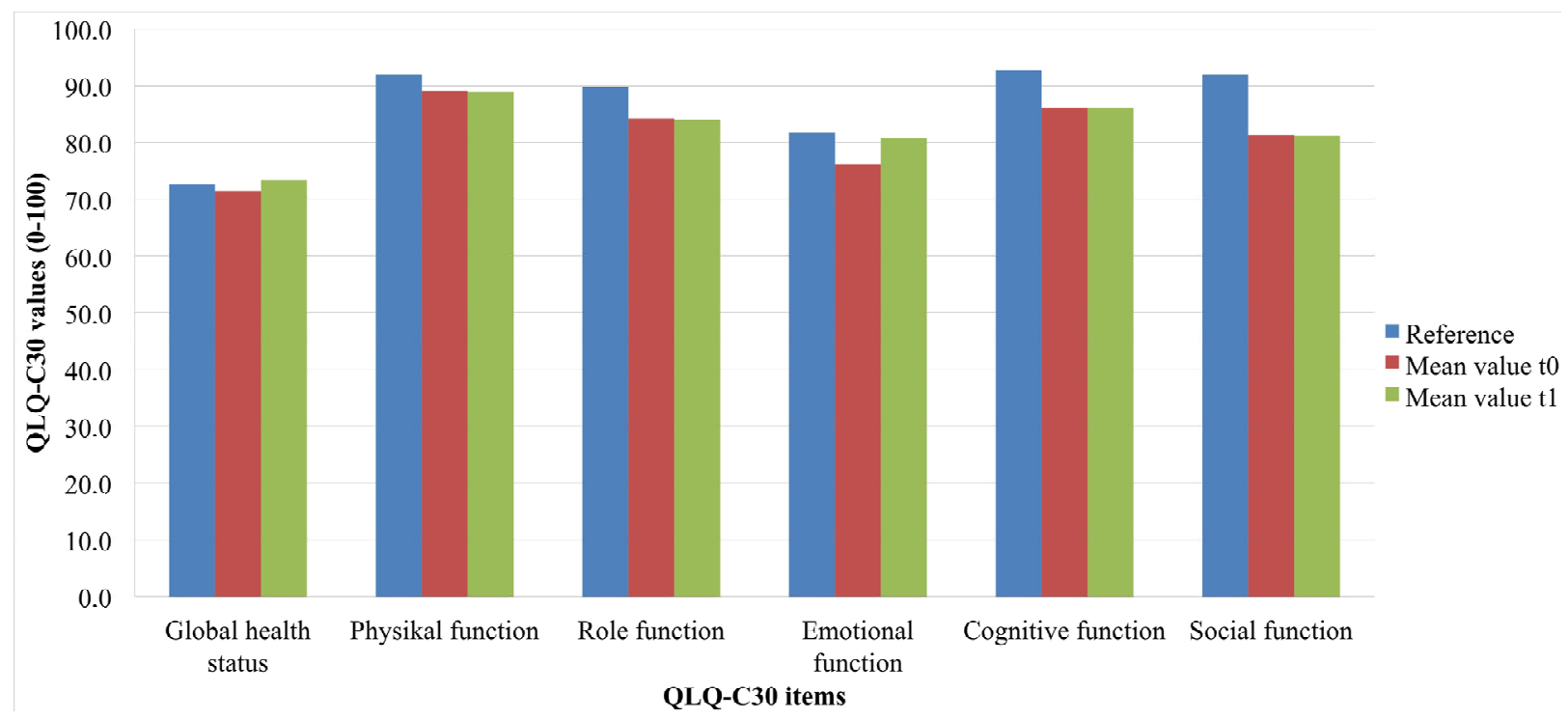

Figure 1. Mean values from the EORTC QLQ-C30 functional scales at $t_{0}$ and $t_{1}$ compared with the reference values for Germany [33]. The functions are rated on a scale of 0 - 100, with higher scores indicating better function [32].

Table 2. Physician empathy by treatment option and point in time. German CARE scale is used to describe the empathy. The score is determined by a five point Likert-skale: 1 $=$ fully applies; 2 = largely applies; $3=$ partially applies; $4=$ hardly applies; 5 = does not apply at all [34].

\begin{tabular}{lcc}
\hline & ${\text { Empathy } \mathbf{t}_{\mathbf{0}}}$ & ${\text { Empathy } \mathbf{t}_{\mathbf{1}}}$ \\
\hline Valid & 1499 & 634 \\
Missing & 394 & 1259 \\
Mean value & 4.59 & 4.53 \\
Standard deviation & 0.59 & 0.66 \\
Watchful waiting & 4.67 & 4.55 \\
Active surveillance & 4.69 & 4.69 \\
Radiation therapy & 4.63 & 4.46 \\
Hormone therapy & 4.63 & 4.66 \\
Radical prostatectomy & 4.56 & 4.50 \\
\hline
\end{tabular}

\subsection{Regression Analysis}

Table 3 shows the results of the linear regression analysis conducted to examine the impact of patient characteristics on the information index. The analysis indicates the following influencing factors on patient information to be significant in localized prostate cancer: Age has a significant impact, as patient information drops with age (beta $-0.030, p=0.02$ ), and significantly fewer men who lived alone were informed (beta $-0.917, \mathrm{p}=0.048$ ). The other sociodemographic items (health insurance, pension, living with spouse) were not significant in any direction. Furthermore, none of the quality of live items, included in the QLQ-C30 instrument, could be identified to have an influence on the patient information in this survey.

In contrast, patients who described their physicians as more empathetic were better informed (beta $0.525, \mathrm{p}=$ 0.000). Also patients who chose the treatment option prostatectomy felt better informed (beta 0.611, $\mathrm{p}=0.020$ ), whereas patients who chose one of the other treatments were not significantly better or less informed.

\section{Discussion}

The aim of our analysis was to determine how patients with localized prostate cancer are informed at urologist practices in Germany and to identify the types of patients that are better or more poorly informed by evaluating patient characteristics. Studies have shown that the information needs of patients vary strongly, and there are indications that these needs are often not fully met. The present study found room for improvement in terms of communicating with prostate cancer patients. On a positive note, the majority of patients at both measurement times had been informed about the various treatment options. Considerably fewer men were informed about rehabilitation options, although the benefit of such measures has already been proven.

The least information was provided about self-help groups, despite the fact that studies indicate that physician attitudes toward these groups are very positive [35]. Moreover, such groups clearly benefit patients [28-30]. The regression analysis reveals influencing factors that must be further clarified. Fortunately, the patients in our sample do not report a significant reduction in their quality of life; their scores were almost as high as in the 


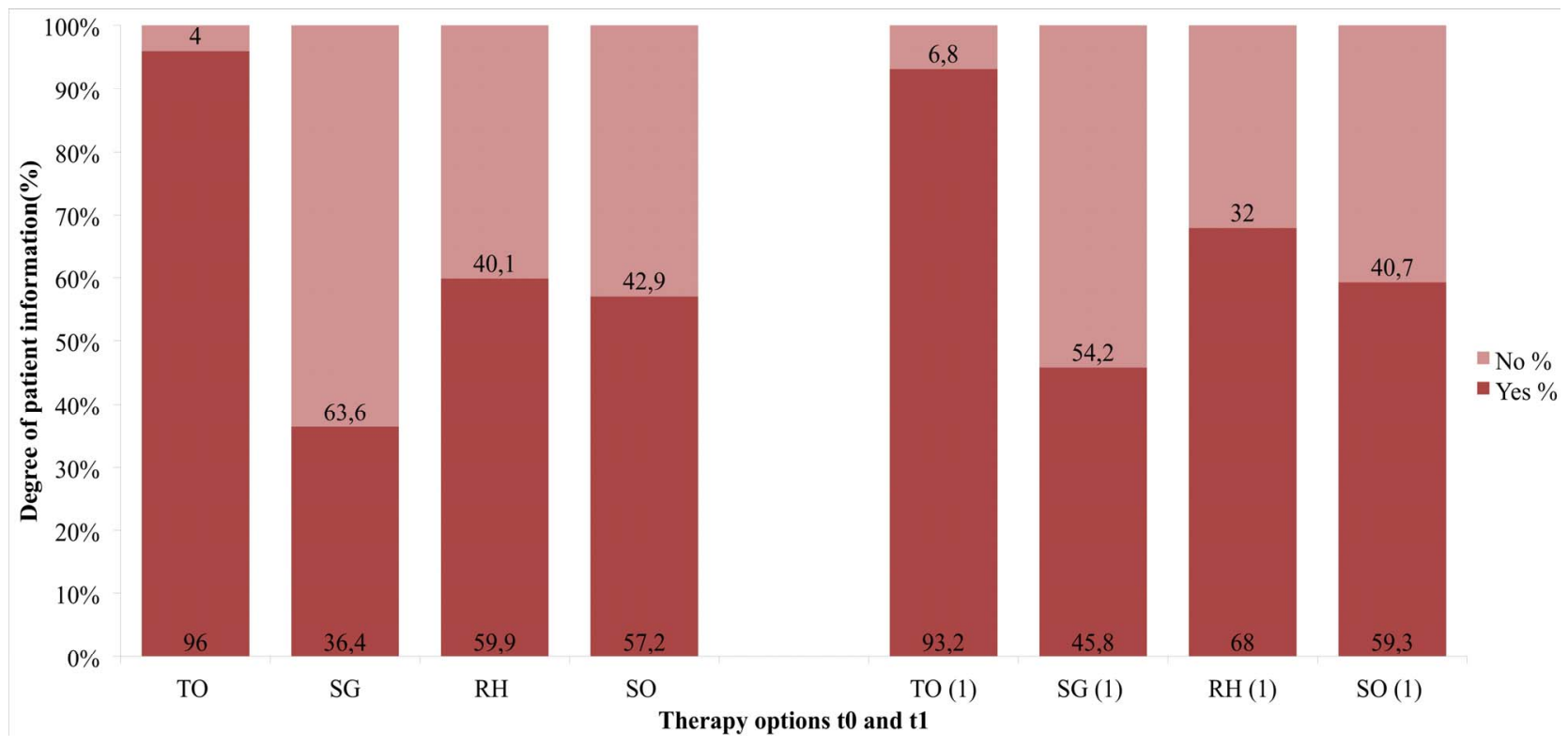

Figure 2. Shows the percentaged degree of patient information for each of the four information questions from HAROW questionnaire. "Yes" means that the patient has been informed about the item; "No" means that he has not been informed. Abbreviations: $\mathrm{TO}=$ treatment options; $\mathrm{SG}=$ self-help groups; $\mathrm{RH}=$ rehabilitation; $\mathrm{SO}=$ second opinion.

Table 3. Results of all four steps of the regression analysis (significant values printed in bold, ${ }^{*}=$ regression koeffizient).

\begin{tabular}{|c|c|c|c|c|c|c|c|c|c|c|c|c|}
\hline \multirow[t]{2}{*}{ Independent Variable } & \multicolumn{3}{|c|}{ Model 1} & \multicolumn{3}{|c|}{ Model 2} & \multicolumn{3}{|c|}{ Model 3} & \multicolumn{3}{|c|}{ Model 4} \\
\hline & Beta $^{*}$ & SD & p-value & Beta $^{*}$ & SD & p-value & Beta $^{*}$ & SD & p-value & Beta $^{*}$ & SD & p-value \\
\hline Age & -0.04 & 0.01 & $<10^{-3}$ & -0.04 & 0.01 & $<10^{-3}$ & -0.04 & 0.01 & $<10^{-3}$ & -0.03 & 0.01 & $<0.01$ \\
\hline Living alone & -0.99 & 0.51 & 0.05 & -0.92 & 0.51 & 0.07 & -0.86 & 0.49 & 0.76 & -0.92 & 0.46 & $<0.05$ \\
\hline Living with spouse & -0.57 & 0.46 & 0.22 & -0.55 & 0.46 & 0.23 & -0.52 & 0.44 & 0.25 & -0.62 & 0.43 & 0.15 \\
\hline Health insurance & 0.01 & 0.15 & 0.94 & -0.04 & 0.15 & 0.80 & -0.06 & 0.15 & 0.70 & -0.08 & 0.14 & 0.57 \\
\hline Pension & 0.10 & 0.18 & 0.55 & 0.08 & 0.18 & 0.65 & 0.07 & 0.17 & 0.68 & 0.04 & 0.16 & 0.80 \\
\hline Global Health stat. & & & & 0.01 & 0.00 & 0.04 & 0.00 & 0.00 & 0.38 & 0.00 & 0.00 & 0.61 \\
\hline Physical functioning & & & & 0.00 & 0.01 & 0.55 & 0.00 & 0.01 & 0.84 & 0.00 & 0.00 & 0.62 \\
\hline Role functioning & & & & 0.00 & 0.00 & 0.60 & 0.00 & 0.00 & 0.59 & 0.00 & 0.00 & 0.79 \\
\hline Emotional functioning & & & & 0.00 & 0.00 & 0.85 & 0.00 & 0.00 & 0.61 & $<10^{-3}$ & 0.00 & 0.94 \\
\hline Cognitive functioning & & & & 0.00 & 0.00 & 0.35 & 0.00 & 0.00 & 0.24 & $<10^{-3}$ & 0.00 & 0.93 \\
\hline Social functioning & & & & 0.00 & 0.00 & 0.76 & $<10^{-3}$ & 0.00 & 0.99 & 0.00 & 0.00 & 0.58 \\
\hline Empathy & & & & & & & 0.48 & 0.10 & $<10^{-3}$ & 0.53 & 0.09 & $<10^{-3}$ \\
\hline Watchful waiting & & & & & & & & & & 0.09 & 0.41 & 0.83 \\
\hline Active surveillance & & & & & & & & & & -0.34 & 0.29 & 0.25 \\
\hline Hormone therapy & & & & & & & & & & -0.03 & 0.33 & 0.94 \\
\hline Radiation therapy & & & & & & & & & & 0.10 & 0.29 & 0.74 \\
\hline Prostatectomy & & & & & & & & & & 0.61 & 0.26 & 0.02 \\
\hline Corrected $\mathrm{r}^{2}$ & & & 0.08 & & & 0.09 & & & 0.17 & & & 0.25 \\
\hline
\end{tabular}


healthy population. The high degree of physician empathy is another positive finding and suggests that the majority of patients feel that they are in good hands and are well understood by their urologists. On a positive note, more empathetic physicians apparently tend to provide better patient information. Studies have already demonstrated the extreme variability of patient information needs [14,17]; it is conceivable that the items self-help groups, rehabilitation, and second opinion are relevant only to a small percentage of patients, and that information on these topics was therefore not actively demanded. Some studies have shown that cancer recurrence, side effects, and long-term prognosis are important issues for patients [18]. Nevertheless, the physician has a duty of care toward the patient, that is, the physician should provide information on all treatments and options that may improve diagnosis or optimize treatment. The benefits of rehabilitation and self-help groups have been proven, so the physician should at least mention these topics. Patients who do not wish to take advantage of such offers can still decline them after considering the advice. Patient age was found to be important: older men were significantly more poorly informed. This may be the result of patient-related factors, for instance a low desire for information in older patients [36], a tendency to prefer a paternalistic doctor-patient relationship [37], or insufficient comprehension of medical information [25]. Physicians, in turn, may assume based on previous experience that older patients desire less information or are no longer capable of adequately processing them. The finding that patients who live alone receive less advice is consistent with the results of other studies indicating that relatives often have more questions than the patients themselves [38]. They want the best for their family member, might be well prepared in consultations, and, as a result, the patients might be better informed. In terms of treatment options, our results show that patients who chose radical prostatectomy are better informed than patients in other treatment groups. This may be a result of the fact that radical prostatectomy is still the most important treatment option in clinical practice and many urologists rather quickly gravitate toward this option since it is often the only curative treatment, although risks and sequelae must be considered for the individual patient.

\subsection{Limitations}

The present data should be interpreted carefully due to limitations resulting from the study design. The urologists knew that they were being observed, which might have led them to focus on being empathetic and making a greater than normal effort with the patient. It is conceivable that only particularly motivated physicians with good interpersonal skills may have agreed to participate in the study, which also could explain the good results regarding physician empathy. In addition, the study only examined patients with localized prostate cancer (see inclusion criteria in the methods section). Therefore, these results may not apply to all prostate cancer patients.

\subsection{Conclusion}

The study raises several questions for future health services research. Future studies should investigate whether the identified deficits only apply to patients with localized prostate cancer or to other patients as well. It must be clarified why older patients and those living alone do not receive as much patient information. The development of evaluated tools for patient information in the form of needs assessment questionnaires or physician guidelines should be discussed by urologists and patient organizations. Every patient could be provided with a core of basic information that is of essential importance in the treatment of his disease. Additional information could then be supplied to interested patients.

\section{Acknowledgements}

We thank all physicians and patients for taking part in the medical study HAROW. GAZPROM Germania supports the study.

\section{REFERENCES}

[1] G. Husmann, P. Kaatsch, A. Katalinic, J. Bertz, J. Haberland and K. Kraywinkel, "Krebs in Deutschland 2005/ 2006. Häufigkeiten und Trends. 7. Ausgabe,” Robert KochInstitut und Die Gesellschaft der Epidemiologischen Krebsregister in Deutschland ev. (Hrg.), Vol. 7, 2010. http://www.krebsgesellschaft.de/download/KID2010.pdf

[2] American Cancer Society, "Cancer Facts \& Figures 2012," American Cancer Society, Atlanta, 2012, pp. 19-20. http://www.cancer.org/research/cancerfactsfigures/cancer factsfigures/cancer-facts-figures-2012

[3] V. Rhode, A. Katalinic and J. Wasem, "Gesundheitsberichterstattung des Bundes Heft 36: Prostataerkrankungen," Robert Koch Institut (Hrsg.), Berlin, 2007. http://edoc.rki.de/documents/rki_fv/ren4T3cctjHcA/PDF/ 20Vo4CXYDBpeQ_34.pdf

[4] S. R. Epstein and R. M. Street Jr., "Patient-Centered Communication in Cancer Care: Promoting Healing and Reducing Suffering," National Cancer Institute, Bethesda, 2007.

[5] T. Hack, L. Degner and P. Parker, "The Communication Goals and Needs of Cancer Patients: A Review," PsychoOncology, Vol. 14, No. 10, 2005, pp. 831-845; Discussion 846-847. doi:10.1002/pon.949

[6] B. Davison, S. Goldenberg, M. Gleave and L. Degner, "Provision of Individualized Information to Men and 
Their Partners to Facilitate Treatment Decision Making In Prostate Cancer," Oncology Nursing Forum, Vol. 30, No. 1, 2003, pp. 107-114. doi:10.1188/03.ONF.107-114

[7] C. K. Gwede, J. Pow-Sang, J. Seigne, R. Heysek, M. Helal, K. Shade, A. Cantor and P. B. Jacobsen, "Treatment Decision-Making Strategies and Influences in Patients with Localized Prostate Carcinoma," Cancer, Vol. 104, No. 7, 2005, pp. 1381-1390. doi:10.1002/cncr.21330

[8] J. Huber, A. Ihrig, C. G. Huber, B. Hadaschik, S. Pahernik and M. Hohenfellner, "Patientenorientierung und Entscheidungsfindung bei Lokal Begrenztem Prostatakarzinom," Der Urologe, Vol. 50, No. 6, 2011, pp. 691696. doi:10.1007/s00120-011-2587-6

[9] S. Steginga, E. Turner and J. Donovan, "The DecisionRelated Psychosocial Concerns of Men with Localised Prostate Cancer: Targets for Intervention and Research," World Journal of Urology, Vol. 26, No. 5, 2008, pp. 469474. doi:10.1007/s00345-008-0279-7

[10] H. Cohen and N. Britten, "Who Decides about Prostate Cancer Treatment? A Qualitative Study," Family Practice, Vol. 20, No. 6, 2003, pp. 724-729. doi:10.1093/fampra/cmg617

[11] F. Fang, N. Keating, L. Mucci, H.-O. Adami, M. Stampfer, U. Valdimarsdottir and K. Fall, "Immediate Risk of Suicide and Cardiovascular Death after a Prostate Cancer Diagnosis: Cohort Study in the United States," Journal of the National Cancer Institute, Vol. 102, No. 5, 2010 pp. 307-314. doi:10.1093/jnci/djp537

[12] V. Nanton, A. Docherty, C. Meystre and J. Dale, "Finding a Pathway: Information and Uncertainty along the Prostate Cancer Patient Journey," British Journal of Health Psychology, Vol. 14, Pt. 3, 2009, pp. 437-458. doi:10.1348/135910708X342890

[13] N. Davies, G. Kinman, R. Thomas and T. Bailey, "Information Satisfaction in Breast and Prostate Cancer Patients: Implications for Quality of Life," Psycho-Oncology, Vol. 17, No. 10, 2008, pp. 1048-1052. doi:10.1002/pon.1305

[14] D. Feldman-Stewart, M. D. Brundage, C. Hayter, P. Groome, J. C. Nickel, H. Downes and W. J. Mackillop, "What Questions Do Patients with Curable Prostate Cancer Want Answered?" Medical Decision Making, Vol. 20, No. 1, 2000, pp. 7-19. doi: $10.1177 / 0272989 \times 0002000102$

[15] D. Feldman-Stewart, S. Brennenstuhl, M. D. Brundage and D. R. Siemens, "Overall Information Needs of EarlyStage Prostate Cancer Patients over a Decade: Highly Variable and Remarkably Stable," Supportive Care in Cancer, Vol. 17, No. 4, 2009, pp. 429-435. doi:10.1007/s00520-008-0514-1

[16] D. Feldman-Stewart, C. Capirci, S. Brennenstuhl, C. Tong, U. Abacioglu, M. Gawkowska-Suwinska, F. van Gils, A. Heyda, S. Igdem, V. Macias, I. M. Grillo, C. Moynihan, M. Pijls-Johannesma, C. Parker, N. Pimentel and H. Wordehoff, "Information Needs of Early-Stage Prostate Cancer Patients: A Comparison of Nine Countries," Radiotherapy and Oncology, Vol. 94, No. 3, 2010, pp. 328-333. doi:10.1016/j.radonc.2009.12.038

[17] R. Schaffert, P. Ruesch, R. Gugler, S. Fischer, H.-P.
Schmid, P. Sporri, M. Zurkirchen and R. Ruszat, "Informationsbedurfnisse von Prostatakrebspatienten. Grosse Individuelle Unterschiede nach Diagnose eines Lokalisierten Prostatakarzinoms," Der Urologe, Vol. 50, No. 9, 2011, pp. 1089-1094. doi:10.1007/s00120-011-2626-3

[18] E. W. Boberg, D. H. Gustafson, R. P. Hawkins, K. P. Offord, C. Koch, K. Y. Wen, K. Kreutz and A. Salner, "Assessing the Unmet Information, Support and Care Delivery Needs of Men with Prostate Cancer," Patient Education and Counseling, Vol. 49, No. 3, 2003, pp. 233-242. doi:10.1016/S0738-3991(02)00183-0

[19] J. Hall, J. Boyd, M. Lippert and D. Theodorescu, "Why Patients Choose Prostatectomy or Brachytherapy for Localized Prostate Cancer: Results of a Descriptive Survey," Urology, Vol. 61, No. 2, 2003, pp. 402-407. doi:10.1016/S0090-4295(02)02162-3

[20] S. K. Steginga, S. Occhipinti, R. A. Gardiner, J. Yaxley and P. Heathcote, "Making Decisions about Treatment for Localized Prostate Cancer," BJU International, Vol. 89, No. 3, 2002, pp. 255-260. doi:10.1046/j.1464-4096.2001.01741.x

[21] E. S. Holmboe and J. Concato, "Treatment Decisions for Localized Prostate Cancer: Asking Men What's Important," Journal of General Internal Medicine, Vol. 15, No. 10, 2000, pp. 694-701. doi:10.1046/j.1525-1497.2000.90842.x

[22] D. Feldman-Stewart, M. D. Brundage, C. Hayter, P. Groome, J. C. Nickel, H. Downes and W. J. Mackillop, "What Prostate Cancer Patients Should Know: Variation in Professionals' Opinions," Radiotherapy and Oncology, Vol. 49, No. 2, 1998, pp. 111-123. doi:10.1016/S0167-8140(98)00091-7

[23] D. Cegala, R. Bahnson, S. Clinton, P. David, M. Gong, J. R. Monk, S. Nag and K. S. Pohar, "Information Seeking and Satisfaction with Physician-Patient Communication among Prostate Cancer Survivors," Health Communication, Vol. 23, No. 1, 2008, pp. 62-69. doi:10.1080/10410230701806982

[24] R. E. Gray, L. H. Klotz, N. A. Iscoe, M. I. Fitch, E. Franssen, B. J. Johnson and M. M. Labrecque, "Prostate Cancer Patients' Satisfaction with Medical Information," The Canadian Journal of Urology, Vol. 4, No. 2, 1997, pp. 83-87.

[25] S. McGregor, "What Information Patients with Localised Prostate Cancer Hear and Understand," Patient Education and Counseling, Vol. 49, No. 3, 2003, pp. 273-278. doi:10.1016/S0738-3991(02)00182-9

[26] S. Snow, R. Panton, L. Butler, D. Wilke, R. Rutledge, D. Bell and R. A. Rendon, "Incomplete and Inconsistent Information Provided to Men Making Decisions for Treatment of Early-Stage Prostate Cancer," Urology, Vol. 69, No. 5, 2007, pp. 941-945. doi:10.1016/j.urology.2007.01.027

[27] D.-H. Zermann, "Der Patient nach Radikaler Prostatektomie,” Der Urologe, Vol. 50, No. 4, 2011, pp. 425-432. doi:10.1007/s00120-010-2481-7

[28] B. Bestmann, T. Kollakowski and L. Weissbach, "Lebensqualitat nach Prostatakarzinom bei Teilnehmern von 
Selbsthilfegruppen,” Der Urologe, Vol. 50, No. 3, 2011, pp. 333-339. doi:10.1007/s00120-010-2491-5

[29] D. Katz, T. Koppie, D. Wu, M. Meng, G. Grossfeld, N. Sadesky, D. P. Lubeck and P. R. Carroll, "Sociodemographic Characteristics and Health Related Quality of Life in Men Attending Prostate Cancer Support Groups," The Journal of Urology, Vol. 168, No. 5, 2002, pp. 20922096. doi:10.1016/S0022-5347(05)64303-0

[30] I. Gregoire, D. Kalogeropoulos and J. Corcos, "The Effectiveness of a Professionally Led Support Group for Men with Prostate Cancer," Urologic Nursing, Vol. 17, No. 2, 1997, pp. 58-66.

[31] N. Ernstmann, O. Ommen, C. Kowalski, M. Neumann, A. Visser, H. Pfaff and L. Weissbach, "A Longitudinal Study of Changes in Provider-Patient Interaction in Treatment of Localized Prostate Cancer," Support Care Cancer, Vol. 20, No. 4, 2012, pp. 791-797. doi:10.1007/s00520-011-1151-7

[32] N. K. Aaronson, S. Ahmedzai, B. Bergman, M. Bullinger, A. Cull, N. J. Duez, A. Filiberti, H. Flechtner, S. B. Fleishman and J. C. Haes, "The European Organization for Research and Treatment of Cancer QLQ-C30: A Qualityof-Life Instrument for Use in International Clinical Trials in Oncology," Journal of the National Cancer Institute, Vol. 85, No. 5, 1993, pp. 365-376. doi:10.1093/jnci/85.5.365

[33] R. Schwarz and A. Hinz, "Reference Data for the Quality of Life Questionnaire EORTC QLQ-C30 in the General German Population," European Journal of Cancer, Vol. 37, No. 11, 2001, pp. 1345-1351.

\section{doi:10.1016/S0959-8049(00)00447-0}

[34] M. Neumann, M. Wirtz, E. Bollschweiler, M. Warm, J. Wolf and H. Pfaff, "Psychometrische Evaluation der Deutschen Version des Messinstruments 'Consultation and Relational Empathy’ (CARE) am Beispiel von Krebspatienten," Psychotherapie, Psychosomatik, Medizinische Psychologie, Vol. 58, No. 1, 2008, pp. 5-15. doi:10.1055/s-2007-970791

[35] S. Steginga, D. Smith, C. Pinnock, R. Metcalfe, R. Gardiner and J. Dunn, "Clinicians' Attitudes to Prostate Cancer Peer-Support Groups," BJU International, Vol. 99, No. 1, 2007, pp. 68-71. doi:10.1111/j.1464-410X.2006.06545.x

[36] A. Robinson and R. Thomson, "Variability in Patient Preferences for Participating in Medical Decision Making: Implication for the Use of Decision Support Tools," Quality in Health Care: QHC, Vol. 10, Suppl. 1, 2001, pp. i34-i38. doi:10.1136/qhc.0100034

[37] A. Moreau, L. Carol, M. C. Dedianne, C. Dupraz, C. Perdrix, X. Laine and G. Soweine, "What Perceptions Do Patients Have of Decision Making (DM)? Toward an Integrative Patient-Centered Care Model. A Qualitative Study Using Focus-Group Interviews," Patient Education and Counseling, Vol. 87, No. 2, 2012, pp. 206-211. doi:10.1016/ j.pec.2011.08.010

[38] S. B. Zeliadt, S. D. Ramsey, D. F. Penson, I. J. Hall, D. U. Ekwueme, L. Stroud and J. W. Lee, "Why Do Men Choose One Treatment over Another?: A Review of Patient Decision Making for Localized Prostate Cancer," Cancer, Vol. 106, No. 9, 2006, pp. 1865-1874. doi:10.1002/cncr.21822 